Research Paper:

\title{
Effect of Group Cognitive Behavioral Therapy on In- efficient Beliefs and Marital Satisfaction in Pregnant Women With the Fear of First Childbirth
}

\author{
Barat Ali Ghavami ${ }^{1}$ (D), Bahram Ali Ghanbari Hashem Abad ${ }^{2 *}$ (D), Mohammad Reza Saffarian ${ }^{3}$ (D), Masoud Khakpour ${ }^{4}$ (D)
}

1. Department of Educational Sciences, Mashhad Branch, Islamic Azad University, Mashhad, Iran.

2. Department of Psychology, Faculty of Education and Psychology, University of Ferdowsi, Mashhad, Iran.

3. Department of Educational Sciences, Mashhad Branch, Islamic Azad University, Iran.

4. Department of Psychology, Hakim Nezami Institute of Higher Education, Quchan, Iran.

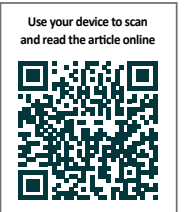

Citation Ghavami BA, Ghanbari Hashem Abad BA, Saffarian MR, Khakpour M. Effect of Group Cognitive Behavioral Therapy on Inefficient Beliefs and Marital Satisfaction in Pregnant Women With the Fear of First Childbirth. Journal of Research \& Health. 2020; 10(1):11-18.

http://dx.doi.org/10.32598/JRH.10.1.11

\section{(1) (8)}

Article info:

Received: 18 Jun 2019

Accepted: 03 Sep 2019

Publish: 01 Jan 2020

Keywords:

Cognitive behavioral therapy, Inefficient beliefs, Marital satisfaction, Fear of childbirth

\begin{abstract}
A B S T RA C T
Background: The present study examined the effect of Group Cognitive Behavioral Therapy (GCBT) on inefficient beliefs and marital satisfaction in pregnant women with the Fear of First Childbirth (FoFC).

Methods: This was a quasi-experimental study with a Pre-test-Post-test and a control group design. The study participants were pregnant women with FoFC who visited Quchan health center in 2018. The study participants were selected using a questionnaire of childbirth fear (as screening) of women with the fear of giving birth. Then, by providing an informed consent form, women volunteering to participate in the project (39 people) were randomly assigned to the experimental (20 people) and control (19 people) groups. The experimental group attended ten 90-minute GCBT sessions. Three questionnaires (Attitude to Childbirth, Jones' Irrational Beliefs, Afrooz Marital Satisfaction) were used to obtain the required data.

Results: The study findings revealed that GCBT significantly affected inefficient beliefs and marital satisfaction in studied pregnant women with FoFC $(\mathrm{P}<0.001)$. Moreover, There was a significant difference between Pre-test and Post-test mean scores in terms of inefficient beliefs and marital satisfaction $(\mathrm{P}<0.001)$.

Conclusion: GCBT was effective in inefficient beliefs and marital satisfaction; thus, this method is recommended to improve the relationship between pregnant women and their spouses during pregnancy.
\end{abstract}




\section{Introduction}

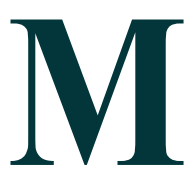

arriage is an important occasion in individuals' life; it meets sexual, cultural, and biopsychosocial needs as an accepted norm throughout the world. The main philosophic ideas of marriage include generation survival, having and loving children, and childbirth. Pregnancy has been considered among essential periods in women's life. Pregnancy extensively changes life. Accepting these changes is too hard for some people. Some women are happy with pregnancy; however, others get upset and disturbed. If disturbances and stresses influence the daily living, requesting for others' assistance will be proposed. Pregnancy is a special event for the expecting mother and her family. Pregnant women face numerous biopsychological changes; if she is unable to accept these changes, she will face many problems. Fear of childbirth is considered as a crucial issue during pregnancy. Researchers have estimated that out of every 5 pregnant women, one experiences like fear [1].

Beliefs are responsible for the healthy and unhealthy control of the mind. Thinking manner defines emotions and methods for controlling them. The cognitive approach believes that suffering from emotional disturbance results from metacognitions in the distinctive patterns of responding to inner experiences; it causes the permanence of negative emotions and beliefs. Cognitive implicit belief causes individuals doubt their ability and sufficiency and this factor affects their mental health. Furthermore, optimistic people enjoy their life and have better biopsychological health.

Moreover, they conduct useful methods when facing mental pressures [2]. Whereas women encounter different stressors during pregnancy, especially the first one, it is expected that these women have a higher vulnerability and be upset and disturbed about childbirth. Other effective factors of fear of childbirth are inefficient beliefs. Examining inefficient and irrational metacognitive beliefs and controlling and reforming those can help pregnant women with childbirth. Inefficient beliefs indicate incorrect thoughts about the world and ones' self. Ellis asserts that no event can inherently generate mental disturbance in people. This is because all events and stimulants are interpreted in mind. According to this approach, emotional problems and conflicts result from interpreting, defining, and processing the achieved data of inefficient thoughts and beliefs. Concerning his approach, mental problems result from incorrect cognitions, beliefs, and views. Irrational beliefs are exaggerated, inflexible, absolute, and unreal. Attitude toward life's events and their interpretation can influence different life aspects. Inefficient attitudes result in depression and mental problems. Inefficient attitudes and beliefs lead to negatively interpreting special situations.

Inefficient mental representation and negative cognitive structures occur in coditions when one negative event activates inefficient schemes. Negative schemes persist due to using incorrect logic. For example, people over-generalize unimportant subjects or over-pay attention to negative points [3]. Therefore, recognizing beliefs and thoughts, especially the incorrect one, is necessary. Inefficient thoughts negatively impact individuals' mental health. Possibly, stresses and pressures make no spontaneous disturbance and tension; however, the relations between different pressures and individuals' perceptions of the situation and their reaction to them can endanger their mental health. Consequently, vulnerability against stress and different problems can cause different psychological issues [4].

Women with few inefficient beliefs during pregnancy feel few pains and can control their stress. As a result, individuals should be influenced by positive thoughts for making compatibility and efficiency. People with limited inefficient thoughts enjoy better mental health. Generally, inefficient attitudes are beliefs and thoughts causing depression and mental disturbance. These beliefs are acquired through experience in relation to oneself and the world.

Additionally, they prepare individuals to interpret particular situations as overly negative and ineffective [5]. Marital satisfaction is effective in women's life and pregnancy. Marital satisfaction is a positive and pleasurable attitude; spouses experience different aspects of marital relations, such as relationships, personality issues, conflict resolution, sexual relations, and having children. Marital satisfaction reflects situations where couples are satisfied with their relations; marital dissatisfaction results from dissatisfaction with relations [6]. Couples who are satisfied with their marital life, have a positive mental attitude to their paired relationship and feel happy [7]. Marital satisfaction is effective in family durability and creates psychological health in couples, children, and society. Marital satisfaction is a basis for the family's optimal performance and plays a vital role in facilitating parents' roles, increasing health, progressing marital life's satisfaction, improving marital conflicts management, decreasing couple's mental problems, and increasing marriage longevity [8]. Self-kindness, couples' communication styles, personality features, and couple's interaction manners are effective in marital satisfaction [9-10]. 
Furthermore, sexual relationship satisfaction is another significant variable in developing and maintaining a happy marital life [11]. In addition, there is a relationship between irrational beliefs and marital conflict severity [12]. Prior studies reported the effectiveness of cognitive-behavioral interventions on marital satisfaction [13-14].

Therefore, cognitive behavioral therapy increases the ability of pregnant mothers to be emotionally available and responsible for their children. Cognitive-behavioral therapy focuses on identifying problems in the mother to confront abnormal knowledge about motherhood. Psychological interventions for pregnant women, especially women who experience the first pregnancy, are necessary; however, data in this regard are scarce. Therefore, the present study aimed to improve marital satisfaction and increase effective thinking in this population. We hope to help the clinical specialists and health center directors with a proper understanding of the effects of cognitive behavioral interventions on the inefficient thoughts and marital satisfaction in pregnant women. Moreover, it is proposed to help further researches. Thus, we explored the effect of GCBT on inefficient thoughts and marital satisfaction among pregnant women in terms of their first childbirth.

\section{Methods}

This was a quasi-experimental study with a Pre-testPost-test and a control group design. The study population included all women with the fear of childbirth referring to the health centers of Quchan City, Iran, in 2018 (245 women).

Accordingly, using the Morgan table, 150 women were selected. After the implementation of the fear of delivery, 39 women who were afraid of delivery and volunteer to participate in the study were selected. Then, using fear of childbirth questionnaire (as screening), women diagnosed with childbirth fear (39 women) were randomly assigned to the experimental (20 women) and control (19 women) groups. The inclusion criteria were first birth, age: $<30$ years, and no history of abortion. Exclusion criteria were unwillingness to continue cooperation in research. The experimental group received GCBT; however, there was no intervention for the control group. The below tools were used in this research:

\section{Childbirth Attitude Questionnaire (CAQ)}

it was developed by Herman and revised by Lowe. It measures the fear of childbirth [15]. This questionnaire has 11 items, and its scoring is based on a 4-point Likert-type scale (never, hardly, sometimes, \& always). Higher scores indicate higher childbirth fear. The Persian version of this questionnaire has appropriate reliability and content validity. Its reliability and content validly were approved by different psychological specialists. The internal consistency and confirmatory of the questionnaire were reported as 0.83 by Andaroon, Kordi and Kimiaei [16]. The same rate was reported equal to 0.87 by Delavar Gavam and Alizadeh Goradel [17]. In the present project, its Cronbach's alpha coefficient was achieved as 0.81 .

\section{Jonez Irrational Beliefs Questionnaire}

This 40-item scale was designed by Jonez (1986) based Ellis's (1962) views. This is among the most useful measuring instruments for irrational beliefs. It consists of 10 subscales, as follows: expectations from others for conformation, over expectation from oneself, reproaching others and oneself, reaction to weakness and disappointment, emotional irresponsibility, disturbed attention, avoiding problems, dependence, weakness against changing, and idealism. This scale's short form was designed by Motamedin et al. in Iran [18].

They omitted 60 out of 100 factors after analyzing the questionnaire, and they made a four-factor instruction for it. Jonez (1968) reported that the 10 factors of the internal consistency of irrational beliefs ranged from 0.45 to 0.72 . He reported its coefficient as 0.92 and its validity as 61.0. Nilson and Hooran (1996) reported the range of 0.810.70 for irrational test reliability using Cronbach's alpha coefficient and 0.85 and 0.73 by ranking. For the 40 factors, a sample of this questionnaire was used (Cronbach's alpha coefficient for measuring test reliability and internal consistency). Its total Cronbach's alpha coefficient was calculated as 0.75 ; it was 0.80 for weakness against changing, 0.81 for expectations from others, 0.73 for avoiding problems, and 0.75 for emotional irresponsibility. Its reliability (using split-half method) was achieved as 0.76 for the total test; it was $0.82,0.84,0.74,0.72$ for the factors mentioned above, respectively. The construct validity of this questionnaire has been reported as acceptable by Motamedin and colleagues. Moreover, they used convergent validity for it. The convergent validity of this test (with 100 questions) was equal to 0.87 [18].

\section{Afrooz Marital Satisfaction Scale (AMSS)}

This tool has been developed by Afrooz and Ghodrati (2011) for measuring marital satisfaction. It has 51 items and 10 subscales. All questions are scored as follows: I completely disagree, I disagree, I agree, I completely agree, by a Likert-type scale. High scores reflect high 
marital satisfaction. The questionnaire has been examined by 8 psychologists and counselors in terms of validity and reliability, and some questions have been omitted, accordingly. Moreover, the questionnaire has been examined by 20 couples; 51 questions have been eventually selected. Afrooz reliability satisfaction scale was conducted along with Enrich's marital satisfaction questionnaire on 60 couples for measuring concurrent validity. The obtained coefficient between the tools of Afrooz and Enrich was achieved as $0.431(\mathrm{P}<0.001)$. Therefore, there was a significant correlation between the two scales. Moreover, the correlation coefficient of subscales and the total scale were statistically significant $(\mathrm{P}<0.001)$. Ten components $>0.3$ were achieved using factor analysis method for examining scale construct validity of couples' satisfaction. Moreover, coefficients between subscales and total scale revealed this scale's effectiveness and efficiency.

Cronbach's alpha coefficient was used for examining scale reliability. The internal coefficient for the total scale was obtained as 0.95 ; it ranged from 0.62 to 0.86 for the subscales. The achieved coefficients revealed appropriate reliability for the scale measuring the couple's satisfaction. The retest reliability coefficient was calculated as 0.74 ; it revealed the great internal coincidence and reliability of that scale. The retest reliability coefficient of it was explored among 60 couples in 20 days and the achieved score was 0.79 ; it was also significant at $\mathrm{P}<0.05$. Reliability coefficients (Cronbach's alpha coefficient) were calculated as $0.85,0.81,0.85,0.83,0.86$, $0.73,0.64,0.75,0.76$, for the subscales, respectively and the total satisfaction coefficient was 0.95 [19].

All study participants completed the questionnaires at [pretest-posttest phases and carefully expressed their ideas. The pretest-posttest stages were conducted in groups. Educational intervention sessions were continuously held in three months and weekly and every 7 days at Mehrafarin counseling center. The study participants were 20 women at each meeting without absences. The questionnaires were distributed in the first session before the intervention (pretest), and in the last session (posttest) Completing questionnaires lasted about 30 minutes.

In the present study, counseling sessions were held for the experimental group members after selecting and replacing subjects. Cognitive-behavioral therapy was performed in each weekly 90 -minute session and for about 3 months in ten 90 -minute sessions by the fourth author (PhD. in Family Counseling) by using Dattilio's method [20].
First Session: Effective factors of a healthy life, present life, and the acceptance of living conditions.

Second Session: Self-examination (meeting the thoughts, analyzing the thoughts, and discovering the strength viewpoints of oneself and others).

Third Session: Effective communication skills, training about interpersonal problem-solving, and assertiveness skills.

Fourth Session: The role of beliefs in emotional and behavioral consequences and training about the threecolumn table (thoughts, emotions, and behaviors).

Fifth Session: Training cognitive errors and its effect on three levels of cognition.

Sixth Session: Stress-relieving and challenging negative thoughts by rejecting thoughts' source, challenging, and stopping negative thoughts.

Seventh Session: Analyzing the relationship between unfortunate events and behavioral changes arising from them.

Eighth Session: Modifying pessimistic thinking styles into optimistic ones.

Ninth Session: Self-discussion (evidence of your interpretation, others' interpretations, and examining beliefs' efficiency) and future planning.

Tenth Session: Meeting self-acceptance skills, self-esteem, concentrating on abilities, disbelieving disabilities.

\section{Results}

The Mean \pm SD age of experimental and control groups were $26.6 \pm 3.8$ and $27.3 \pm 3.5$ years, respectively. The educational level of the experimental group was as follows: 2: no degree, 8: diploma, 6: bachelor's degree, 4: master's degree). Moreover, marriage duration Mean \pm SD scores of the experimental and control groups were $3.2 \pm 1.3$ and $3.7 \pm 1.5$ years, respectively. Table 1 lists descriptive indexes (Mean $\pm \mathrm{SD}$, minimum, \& maximum) of inefficient beliefs and marital satisfaction in the experimental and control groups in pretest-posttest stages.

As shown in Table 1, the mean Post-test scores of the experimental group decreased in terms of inefficient beliefs questionnaire compared to the Pre-test scores. However, there was no significant change in the control group. Moreover, the mean Post-test scores of the experimental group increased in the marital satisfaction 
Table 1. The descriptive characteristics of inefficient beliefs and marital satisfaction in the study group

\begin{tabular}{|c|c|c|c|c|c|c|c|c|c|}
\hline \multirow{2}{*}{ Variable } & \multirow{2}{*}{ Group } & \multicolumn{4}{|c|}{ Pre-test } & \multicolumn{3}{|c|}{ Post-test } & \multirow{2}{*}{$\mathbf{P}$} \\
\hline & & Mean $\pm S D$ & Min. & Max. & $\mathbf{P}$ & Mean $\pm S D$ & Min. & Max. & \\
\hline \multirow{2}{*}{$\begin{array}{c}\text { Inefficient } \\
\text { beliefs }\end{array}$} & Experimental & $123.13 \pm 9.5$ & 80 & 135 & \multirow{2}{*}{0.198} & $104.2 \pm 8.1$ & 75 & 115 & \multirow{2}{*}{0.001} \\
\hline & Control & $121.5 \pm 9.1$ & 78 & 130 & & $120.1 \pm 8.7$ & 73 & 123 & \\
\hline \multirow{2}{*}{$\begin{array}{c}\text { Marital } \\
\text { satisfaction }\end{array}$} & Experimental & $91.5 \pm 6.5$ & 71 & 104 & \multirow{2}{*}{0.147} & $126.2 \pm 8.3$ & 79 & 127 & \multirow{2}{*}{0.001} \\
\hline & Control & $90.8 \pm 7.1$ & 72 & 102 & & $91.4 \pm 7.5$ & 73 & 104 & \\
\hline
\end{tabular}

URA

questionnaire compared to the pre-test scores. However, there was no significant change in the control group. Multivariate Analysis of Covariance (MANCOVA) was used for examining the research hypothesis. Initially, the most critical assumptions necessary for MANCOVA were examined. Intended scales had no problem (e.g. skewness, etc.) in the study sample. Moreover, the Kolmogorov-Smirnov test was used for examining the normality of the obtained data. Normality was observed for all subscales $(\mathrm{P}>0.05)$. Moreover, the variable's reliability existed as another MANCOVA assumption. Besides, there was a homogeneity hypothesis of error variance and the homogeneity hypothesis of regression's slope.

MANCOVA results revealed a statistically significant difference between questionnaire' mean scores mean in the inefficient marital beliefs and marital satisfaction for the experimental and control groups after modifying the Pre-test scores. Pillai's trace, Wilks' Lambda, Hotelling's Trace and Roy's Largest Root significance level $(0.0003)$ was $<0.005$; it revealed a minimum difference between one dependent variable (inefficient beliefs with marital satisfaction) in the experimental and control groups. In other words, GCBT positively affected one of the dependent variables (inefficient beliefs with marital satisfaction). The effect of GCBT has been examined on every dependent variable for determining its effect on one of the dependent variables (inefficient beliefs with marital satisfaction). Levene's test was used to check the variance homogeneity. To test it for the same variance, this test should not be statistically significant (a significant level $>0.05$ ). If the significance level is $<0.05$, then the variance of the groups is not the same and the as- sumption of the homogeneity of the variances is violated. Levene's test results are reported in Table 2.

Based on Table 2, the significance level for the dependent variable was $>0.05$. Therefore, the homogeneous assumption of error variances was established. To prove the assumption of slope coherence, the F-value of the interaction between the Pre-test and the group should not be significant. This assumption relates to the relationship between the variable of change and the dependent variable for each group. What is being examined here is the existence or absence of interactions between the variables, either interference or experimental manipulation. If the interaction is significant at $\mathrm{P}=0.05$, this notion is being violated. The result of the tensile homogeneity test of the regression line is also presented in Table 3. As shown in Table 4, the significance level of interaction in two dependent variables is $>0.05$. Therefore, the homogeneity assumption of the slope of the regression line exists, as the default. The results of the homogeneity test and regression line tilt homogeneity test for dependent variables are indicated in inefficient beliefs $(\mathrm{F}=0.357$, $\mathrm{P}=0.706)$ and marital satisfaction $(\mathrm{F}=0.897, \mathrm{P}=0.430)$. Thus, $\mathrm{P}>0.05$ was the significance level.

According to Table 3, the significance level of F (0007) in marriage's inefficient beliefs has been $<0005$; therefore, GCBT had a significant effect on pregnant women's fear of first childbirth. Therefore, the hypothesis of the research has been confirmed with $95 \%$ confidence. Additionally, GCBT explained $25.5 \%$ of the inefficient beliefs variance of pregnant women with the fear of first childbirth concerning the eta-squared contribution. Ac-

Table 2. Levene's test results regarding examining the homogeneity assumption of error variances

\begin{tabular}{ccccc}
\hline Variable & df1 & df2 & F & P \\
\hline Inefficient beliefs & 1 & 36 & 0.180 & 0.674 \\
Marital satisfaction & 1 & 36 & 1.646 & 0.210
\end{tabular}


Table 3. ANCOVA results for inefficient beliefs questionnaire scores

\begin{tabular}{lccccccc}
\hline \multicolumn{1}{c}{ Variable } & Changes & Sum of Squares & df & Mean Squared & F & P & Eta-Squared \\
\hline \multirow{2}{*}{ Inefficient beliefs } & Factor & 428.327 & 1 & 428.327 & & & 0.255 \\
& Error & 1398.177 & 36 & 63.553 & & 0.007 & \\
\multirow{2}{*}{ Marital satisfaction } & Factor & 3083.175 & 1 & 3083.175 & & & 0.375
\end{tabular}

Table 4. Modified Post-test Mean \pm SD scores of inefficient beliefs and marital satisfaction

\begin{tabular}{cccc}
\hline Variable & Phase & Group & Mean \pm SD \\
\hline $\begin{array}{c}\text { Inefficient } \\
\text { beliefs }\end{array}$ & post-test & Experimental & $103.7 \pm 8.1$ \\
& & Control & $119.7 \pm 8.7$ \\
Marital satisfaction & post-test & Experimental & $125.9 \pm 8.01$ \\
& & Control & $91.1 \pm 7.33$ \\
\hline
\end{tabular}

cording to Table 4, the significance level (0001) of $\mathrm{F}$ in marital obligation Post-test was $<0005$; it revealed that GCBT significantly affected marital satisfaction in pregnant women with the fear of first childbirth. Therefore, the research hypothesis was confirmed. It was also concluded that GCBT revealed $37.5 \%$ of marital satisfaction variance in pregnant women with the fear of first childbirth concerning the eta-squared contribution.

Groups' modified mean scores are presented in Table 4; concerning unchanged ANCOVA; the effect of Pre-test and calculated modified mean scores are listed. As shown in Table 4, the mean Post-test scores of inefficient marital beliefs were smaller in the experimental group compared to the controls; it suggested the effect of GCBT on the inefficient beliefs of study subjects. In addition, the Posttest mean scores of marital satisfaction were higher in the experimental group, compared to the control group; GCBT was effective on the marital satisfaction of study participants.

\section{Discussion}

The mental health of expecting mothers depends on a desirable relationship with husband and marital and sexual satisfaction $[4,5,21]$.

The study finding revealed a significant relationship between GCBT and inefficient beliefs in pregnant women with the fear of first childbirth. Additionally, GCBT described $25.5 \%$ of inefficient beliefs variance in pregnant women with the fear of first childbirth concerning eta-squared contribution. These findings are in line with those of many research studies $[22,23]$.

Moreover, GCBT significantly influenced marital satisfaction in pregnant women with the fear of the first childbirth. Besides, GCBT described $37.5 \%$ of marital satisfaction variance among the study subjects. Many research studies supported the effect of CBT on marital satisfaction in expecting mothers [6, 20, 21-24]. The most important part of the cognitive-behavioral treatment was discovering interpersonal interferences, like the fear of childbirth [14, 19, 25, 26]. Related beliefs with fear of childbirth are in line with expectations, danger possibility, and rational belief [27, 28]. According to Dattilio, most of the pregnant women have negative beliefs and thoughts [20].

The cognitive-behavioral approach focuses on the relationship between family and the person concerning expectations and beliefs. Therefore, the reframing technique is used for simplifying changes in understanding events and behaviors in these approaches; the bilateral effect of reactions is also examined or behavior rejection technique is used. Cognitive-behavioral therapists examine the problem by concentrating on changing factors or by reforming a person's thinking system about her family or herself or by reforming participatory skills' deficiencies [29].

The cognitive-behavioral approach implies situations in which schemes are essential. Usually, schemes are conflicting factors between couples. Scheme are patterns 
that enter the reality or experience of individuals to help them understand the situation, or it acts as a mediator of perceptions for leading their responses. The major part of the cognitive-behavioral approach is focusing on the thoughts and perceptions and their effects on emotions and behaviors. Often, irrational beliefs disable couples for changing.

Cognitive-behavioral patterns concentrate on the behavioral and emotional responses to life's events, mediated by interpretations related to the thoughts. These interpretations can be perverted or inappropriate. Cognitive-behavioral therapists help couples energetically evaluate their perceptions, reform their negative relations, and develop their positive emotions and cognitions. This is beneficial in having a desirable marital relation. CBT is an organized, qualitative approach for couples to examine understandings, behaviors, and emotions for improving relations and reactions [29].

\section{Conclusion}

GCBT is useful for pregnant women with the fear of first childbirth. It can be added to the couple's therapy as a standard educational program. This project is effective for modifying inefficient beliefs, increasing marital satisfaction and commitment, decreasing the conflicts between couples, increasing therapy's effectiveness, and decreasing divorce rates. When women become aware of their inefficient beliefs, they can control their thoughts; they also would increase their marital quality.

Moreover, this project can be effective for couples and counselors. Counselors can use this approach to help couples to create a healthy family and society. GCBT has significant effects on marital variables; thus, using this model is proposed in other problems related to marital life. There was no specific limitation in the implementation of this study. Therefore, considering the desirable effects of GCBT on pregnant women with the fear of first delivery, it is highly recommended to implement such interventions to reduce the stress of expecting women and increase the health of mother and child.

\section{Ethical considerations}

\section{Compliance with ethical guidelines}

There was no ethical considerations to be considered in this research.

\section{Funding}

The present project is part of a $\mathrm{PhD}$. thesis of Ali Ghavami Barat in Counseling conducted in the Mashhad Azad University (Code: IRCT201712052534N1).

\section{Authors' contributions}

Study design: All author; Data collection and analysis and Manuscript preparation: Ali Ghavami Barat and Masoud Khakpour.

\section{Conflict of interest}

The authors declared no competing interests.

\section{References}

[1] Alipour Z, Lamyian M, Hajizadeh E, Vafaei MA. The association between antenatal anxiety and fear of childbirth in nulliparous women: A prospective study. Iranian J of Nurs and Midwifery Res. 2011; 16(2):169-73.

[2] Pournamdarian S, Birashk B, Asgharnejad F. [The Clarification of contribution of meta-cognitive beliefs in explaining the symptoms of depression, anxiety and stress in nurses (Persian)]. Knowl \& Res in Appl Psychol. 2012; 13(3):55-64.

[3] Ellis A, Dryden W. The practice of rational emotive behavior therapy ( $2^{\text {nd }}$ Ed.). New York: Springer Publishing Company; 2007. [DOI:10.1891/9780826122179]

[4] Biaggi A, Conroy S, Pawlby S, Pariante C. Identifying the women at risk of antenatal anxiety and depression: A systematic review. J of Affect Disord. 2016; 191:62-77. [DOI:10.1016/j.jad.2015.11.014] [PMID] [PMCID]

[5] McEvoy PM, Moulds ML, Mahoney AEJ. Mechanisms driving pre- and post-stressor repetitive negative thinking: Metacognitions, cognitive avoidance, and thought control. J of Behav Ther and Exp Psychiatry. 2013; 44(1):84-93. [DOI:10.1016/j.jbtep.2012.07.011] [PMID]

[6] Ahmadi K, Nabipoor SM, Kimiaee SA, Afzali MH. Effect of family problem solving on marital Satisfaction. J of Appl Sci. 2010; 10(8):682-7. [DOI:10.3923/jas.2010.682.687]

[7] Ramezani S, Keramat A, Motaghi Z, Khosravi A. The relationship of sexual satisfaction and marital satisfaction with domestic violence against pregnant women. Int J of Pediat. 2015; 3(5):951-8

[8] Javidi N. [The Effectiveness of Emotion-Focused Couple Therapy (EFCT) in improving marital satisfaction and family behavior control (Persian)]. Biannual J of Appl Couns. 2014; 3(2):65-78.

[9] Malouff JM, Thorsteinsson EB, Schutte NS, Bhullar N, Rooke SE. The five-factor model of personality and relationship satisfaction of intimate partners: A meta-analysis. J of Res in Personal. 2010; 44(1):124-7. [DOI:10.1016/j.jrp.2009.09.004] 
[10] Bravo IM, Lmpkin PW. The complex case of marital infidelity: An explanatory model of contributory processes tofacilitate psychotherapy. The Am J of Fam Ther. 2010; 38(5):421-32.

[11] Rahmani A, Merghati Khoei E, Sadeghi N, Allahgholi L. [Relationship between sexual pleasure and marital satisfaction (Persian)]. Iran J of Nurs. 2011; 24(70):82-90.

[12] Tikdarinejad A, Khezri Moghadam N. Relationship between irrational beliefs and marital conflicts in couples based on rational-emotive behavior therapy. Patient Saf \& Qual Improv J. 2017;5(2):526-530.

[13] Ucar T, Golbasi Z. Effect of an educational program based on cognitive behavioral techniques on fear of childbirth and the birth process. J of Psychosom Obstet and Gynaecol. 2019; 40(2):146-155. [DOI:10.1080/0167482X.2018.1453800] [PMID]

[14] Mahintorabi S, Mazaheri MA, Sahebi A, Mousavi V. [The effect of cognitive-behavioral training on modification of irrational expectation, emotional maturity and marital dissatisfaction in women (Persian)]. J of Behav Sci. 2011; 5(2):127-34.

[15] Lowe NK. Self-efficacy for labor and childbirth fearsin nulliparous pregnant women. J of Psychosom Obstet and Gynaecol. 2000; 21(4):219-24. [DOI:10.3109/01674820009085591] [PMID]

[16] Andaroon N, Kordi M, Kimiaei SA, Esmaeili H. [Relationship between Intensity of fear of Childbirth with choosing mode of delivery in Primiparous Women (Persian)]. The Iranian J of Obstet, Gynecol and Infertil. 2017; 20(5):67-85.

[17] Delavar Gavam S, Alizadeh Goradel J. [The role of metacognitive beliefs and positive and negative affect in the Fear of childbirth of pregnant women with first experience (Persian)] Iranian J of Nurs Res. 2014; 9(3):10-18.

[18] Motamedin M, Badri R, Ebadi GH, Zamani N. [Standardization of the Irrational Beliefs (4IBT-A) (Persian)]. Psychol Methods and Model. 2012; 2(8):71-86.

[19] Fazilati M, Afrooz GA, Alipour A, Hantooshzadeh S. [Efficacy of family-based psychological interventions on marital satisfaction of pregnant mothers and their infants' birth weight (Persian)]. Health Psychol. 2017; 6(23):118-35.

[20] Dattilio FM. The role of cognitive behavioral interventions in couple and family Therapy. J of Marital and Fam Ther. 2005; 10:105-14.

[21] Zare Z, Golmakani N, Shareh H, Shakeri MT, KhademGhaebi N. Factors related to marital satisfaction in primiparous women during postpartum period. J of Midwifery and Reprod Health. 2014; 2(2):120-7.

[22] Forsell E, Bendix M, Holländare F, Szymanska B, Schultz V, Nasiell J. Internet delivered cognitive behavior therapy for antenatal depression: A randomized controlled trial. J of Affect Dis. 2017; 221:56-64. [DOI:10.1016/j.jad.2017.06.013] [PMID]

[23] Rondung E, Thomtén J, Sundin O. Psychological perspectives on fear of childbirth. J of Anxiety Dis. 2016; 44:80-91. [DOI:10.1016/j.janxdis.2016.10.007] [PMID]

[24] Rouhe H, Salmela-Aro K, Toivanen R, Tokola M, Halmesmäki E, Ryding EL. Group psycho education with relaxation for severe fear of childbirth improves maternal adjustment and childbirth experience-a randomized controlled trial. J of Psychosom Obstet and Gynaecol. 2015; 36(1):1-9. [DOI:10.3109/0167482X.2014.980722] [PMID]
[25] Javidi N. The [Effectiveness of Emotion-Focused Couple Therapy (EFCT) in improving marital satisfaction and family behavior control (Persian)]. Biannual J of Appl Couns. 2013; 3(2):65-78.

[26] Babakhani N, Taravati M, Masoumi Z, Garousian M, Faradmal J, Shayan A. [The effect of cognitive-behavioral consultation on sexual function among women: A randomized clinical trial (Persian)]. J of Caring Sci. 2018; 7(2):83-8. [DOI:10.15171/jcs.2018.013] [PMID] [PMCID]

[27] Khorsandi M, Ghofranipour F, Heydarnia A, FaghihZadeh S, Vafaei M, Rousta F, et al . [The effect of childbirth preparation classes on childbirth fear and normal delivery among primiparous women (Persian)]. J of Arak Univ of Med Sci. 2008; 11(3):29-36

[28] Striebich S, Mattern E, Ayerle GM. Support for pregnant women identified with fear of childbirth (FOC)/ tokophobia - A systematic review of approaches and interventions. Midwifery. 2018; 61:97-115. [DOI:10.1016/j.midw.2018.02.013] [PMID]

[29] Dobson KS. Handbook of cognitive-behavioral therapies, fourth edition. New York: Guilford Press; 2011. 